\title{
ELECTROCHEMICAL AND ELLIPSOMETRIC DATA RELATED TO THE FORMATION OF SOLUBLE SILVER (I) DURING THE POTENTIODYNAMIC POLARIZATION OF POLYCRYSTALLINE SILVER IN BASIC SOLUTIONS
}

\author{
J. Zerbino, M. Lopez Teijelo, J. R. Vilche and A. J. Arvia
}

\begin{abstract}
Instituto de Investigaciones Fisicoquimicas Teoricas y Aplicadas--INIFTA, Casilla de Correo 16, Sucursal 4,
\end{abstract} 1900 La Plata, Argentina

(Received 27 January 1985; in revised form 22 April 1985)

\begin{abstract}
Soluble $\mathrm{Ag}(\mathrm{I})$ species is formed in the early stages of voltammetric silver electrooxidation in $0.1 \mathrm{M} \mathrm{NaOH}$ and $0.1 \mathrm{M} \mathrm{NaOH}+1 \mathrm{M} \mathrm{NaClO}_{4}$ solutions at $25^{\circ} \mathrm{C}$, as demonstrated by the rotating ring-disc technique. This result allows a reasonable interpretation of ellipsometric data obtained for the anodization of silver under different voltammetric conditions. Correspondingly, two anodic layers of different optical constants are electroformed. The hydrous $\mathbf{A g ( I )}$ oxide layer behaves as a porous structure with an average thickness of about 2.5 times greater than that of the anhydrous oxide.
\end{abstract}

\section{INTRODUCTION}

The first stages of oxidation of Ag electrodes in alkaline solution involve two forms of adsorbed oxygen on silver[1-10], as studied through electroreflection measurements, and the electrodissolution of the metal as soluble $\mathrm{Ag}(\mathrm{I})$ species [7-9]. The kinetics associated with the formation of thicker $\mathrm{Ag}_{2} \mathrm{O}$ layers also revealed two stages of $\mathrm{Ag}_{2} \mathrm{O}$ formation[11-17]. The solubility of $\mathrm{Ag}_{2} \mathrm{O}$ in the monolayer region and for massive layers increases with the KOH concentration up to a maximum value at $c a 6 \mathrm{M} \mathrm{KOH}[11]$.

The voltammetric electrooxidation of silver in alkaline solution is characterized by three current peaks. The first anodic voltammetric peak for the electrooxidation of silver in alkaline solution is independent of sweep rate $(v)$ at all temperatures[18] but the third anodic voltammetric peak shifts to more positive potentials with increasing sweep rate at each temperature. The complexity of the redox mechanism is indicated by the nonlinearity of peak potential $v s \ln v$, and by linear peak current $v s v^{1 / 2}$ plots which do not pass through the origin. A surface roughness factor is required for a satisfactory explanation of the impedance data together with electron microscopy examination which shows that an initially smooth silver surface after a single triangular potential scan transforms into sponge- or gel-like surface structure with an area increase[19]. Furthermore, anodically formed $\mathrm{Ag}_{2} \mathrm{O}$ layers after reduction, either electrochemically or in hydrogen at $800^{\circ} \mathrm{C}$, leave behind a highly porous layer of silver metal 207 .

The linear dependence of the voltammetric anodic current peak at high positive potentials with $v^{1 / 2}[13]$ and current transients at a constant potential step $[14,21,22]$ suggest that a diffusion process associated with the ionic transference in the solid phase, is rate controlling.

Galvanostatic and ellipsometric data of anodic films formed on silver in $0.1-6 \mathrm{M} \mathrm{KOH}$ for currents between
0.2 and $1 \mathrm{mAcm}^{-2}$ were interpreted with a model consisting of six layers [23]. However, the ellipsometric and reflectance responses of silver in $0.1 \mathrm{M} \mathrm{NaOH}$ obtained by applying the potential sweep technique in the potential range of the $\mathrm{Ag}(0) / \mathrm{Ag}(\mathrm{I})$ electrode $[24,25]$ depends substantially on $v$ and on the amount of anodic layer accumulated on the electrode. These results were interpreted in terms of two limiting structures of the anodic film. These structures were characterized by their own complex refraction indexes. The kinetics of these processes was explained through a complex mechanism involving the formation of soluble $\operatorname{Ag}(\mathrm{I})[7,11,24,25]$. A time dependence of the optical parameters related to both the reformed silver surface and the anodic oxide layer was also observed, which was attributed to the proper characteristics of the freshly reformed silver surface produced during the oxide layer electroreduction.

The present work demonstrates that soluble $\mathbf{A g}(\mathbf{I})$ is formed in the early stages of silver electrooxidation in alkaline solutions. Ellipsometric data furnish reasonable values of the optical constants and a satisfactory estimation of the anodic layer average thickness. For this purpose, the freedom of interpretation of the ellipsometric results is greatly reduced if the series of mcasurcments are cvaluated taking the thickncss as a changing parameter with a common set of optical indexes which are at least valid within a certain range of thickness[26, 27].

\section{EXPERIMENTAL}

The ellipsometric data were obtained by using a three-compartment cell made of Pyrex glass. The silver working electrode $\left(0.385 \mathrm{~cm}^{2}\right.$, polycrystalline silver, $99.9999 \%$ purity, Johnson Matthey Chemicals Co.) was mounted in a Teflon holder and horizontally placed in the cell compartment provided with two plane glass windows adequate for optical measure- 
ments. The cell was mounted in a Rudolph Research type 437-02/200 B manual ellipsometer (maximum resolution $0.01^{\circ}$ ) equipped with a $150 \mathrm{~W}$ tungsten lamp with filter (5461 A) and a RCA IP21 photomultiplier. The incidence light beam angle was fixed at $69^{\circ}$ and that of the compensator at $135^{\circ}$. Runs were made at $25^{\circ} \mathrm{C}$. Before each run the working electrode was gradually polished starting with 600 grade emery paper and finishing with 0.05 micron alumina on a microcloth. Finally, the electrode was repeatedly cleaned with distilled water. The potentials in the text are given in the whe scale. The counterelectrode was a spiral shaped Pt wire. The electrolyte solution consisted of either $0.1 \mathrm{M} \mathrm{NaOH}$ or $0.1 \mathrm{M} \mathrm{NaOH}+1 \mathrm{M} \mathrm{NaClO}_{4}$, which were prepared from $\mathrm{NaOH}$ (Merck a.r.), $\mathrm{NaClO}_{4}$ (Merck a.r.) and triply-distilled water. The solutions were continuously kept under $\mathbf{N}_{2}$.

Initially the ellipsometric response at a constant wavelength of the polished Ag electrode under open circuit was determined. The readings at the polarizer $(P)$ and the analyser $(A)$ of initial polished silver yielded values of the refractive index, $\boldsymbol{n}_{s}$, and the absorption coefficient $\left(k_{s}\right)$ of the substrate, which were coincident with those earlier reported in the literature (Table 1).

The contribution of the partial electrodissolution of the anodic layer as soluble $\mathbf{A g}(\mathbf{I})$ was measured with the rotating ring-disc technique at stirring velocities $(\omega)$ up to $3000 \mathrm{rpm}$. The rrde consisted of a silver plated Pt disc $\left(0.125 \mathrm{~cm}^{2}\right)$ and a Pt ring $\left(0.029 \mathrm{~cm}^{2}\right.$, collection efficiency 0.25 ). The ring electrode served for detection and evaluation of the amount of soluble $\mathrm{Ag}(\mathrm{I})$, by measuring the current transient under a constant potential step $\left(E_{R}\right)$. The current response at the ring was recorded at $0.12 \mathrm{~V}$ (vs $n h e$ ) by keeping the disc under a potentiodynamic sweep at the rate of the potential sweep $(v)$ and different anodic $\left(E_{s, a}\right)$ and cathodic $\left(E_{s, c}\right)$ switching potentials.

\section{RESULTS}

\section{Ellipsometric data}

The ellipsometric readings ( $P$ and $A$ ) of the $\mathrm{Ag}$ electrode covered with the anodic layer were made at a constant wavelength $(\lambda=5461 A)$ in different ways. In one case, (procedure $A$ ) the anodic layer corresponding to the charge $Q_{a}$ was firstly formed under a linear potential sweep (lps) from $E_{s, \mathrm{c}}=-0.15 \mathrm{~V}$ up to $E_{s, 4}$ $\left(0.35 \leqslant E_{s, a} \leqslant 0.70 \mathrm{~V}\right)$ at $v\left(2 \times 10^{-4} \leqslant v \leqslant 0.1 \mathrm{Vs}^{-1}\right)$. Immediately after the anodic current at $E_{s, a}$ was switched off $(t=0)$ and the values of $P$ and $A$ were read at different present times counted from $t=0$. Later, the voltammetric growth of the anodic layer was continued from the open circuit potential to another $E_{s, a}$ value. Then, the anodic current was again inter-

Tahle 1. Complex refractive index of silver substrate

\begin{tabular}{cll}
\hline $\bar{n}$ & $\lambda / A$ & Ref. \\
\hline $0.18-i 3.42$ & 5461 & {$[4]$} \\
$0.19-\mathrm{i} 3.80$ & 6328 & {$[8,9]$} \\
$0.18-\mathrm{i} 3.61$ & 5461 & {$[23]$} \\
$0.20-\mathrm{i} 3.62$ & 5461 & {$[25]$, this work } \\
\hline
\end{tabular}

rupted and the values of $P$ and $A$ were read at another open circuit potential. This stepwise procedure to evaluate $P$ and $A$ was repeated so that $E_{s, a}$ covered the potential range related to the $\mathrm{Ag}(\mathrm{I})$ oxide electroformation. Hence, the gradual increase in $Q_{a}$ implied anodic layers of increasing average thicknesses.

The values of $P$ and $A$ were also read without interrupting the positive potential scan (procedure $B$ ). For this purpose runs were made at $2 \times 10^{-4} \mathrm{Vs}^{-1}$ and measurements were performed during the first potential sweep starting from polished Ag electrode surfaces.

In the range of $v$ covered by the present work the values of $P$ and $A$ depend on $Q_{a}$ (Fig. 1). Initially, for $Q_{a}<10 \mathrm{mCcm}^{-2}$, both $P$ and $A$ decrease as $Q_{a}$ increases, although their rates of change are small as compared to the experimental errors. Otherwise, in the $10<Q_{a}<40 \mathrm{mC} \mathrm{cm}^{-2}$ range, both $P$ and $A$ increase with $Q_{a}$, but when $Q_{a}>40 \mathrm{mC} \mathrm{cm}^{-2}$, the rest of the $P$ vs $A$ plot is considerably influenced by the value of $v$. Thus, for $25<Q_{a}<50 \mathrm{mC} \mathrm{cm}^{-2}$, at 0.02 and $0.1 \mathrm{Vs}^{-1}$, an ascending counterclockwise loop is observed in the $P$ vs $A$ plot, while a reverse loop appears at $10^{-3} \mathrm{Vs}^{-1}$. Therefore, one concludes that the properties of the anadic layer depend considerably on $v$. Furthermore, the $P$ vs $A$ plots obtained either from procedure $A$ or B, also change whether the first or the following potential scan is considered [25]. The following evaluation of anodic layer thickness and the corresponding optical constants was performed with data obtained from the first voltammogram run with a polished $\mathrm{Ag}$ electrode.

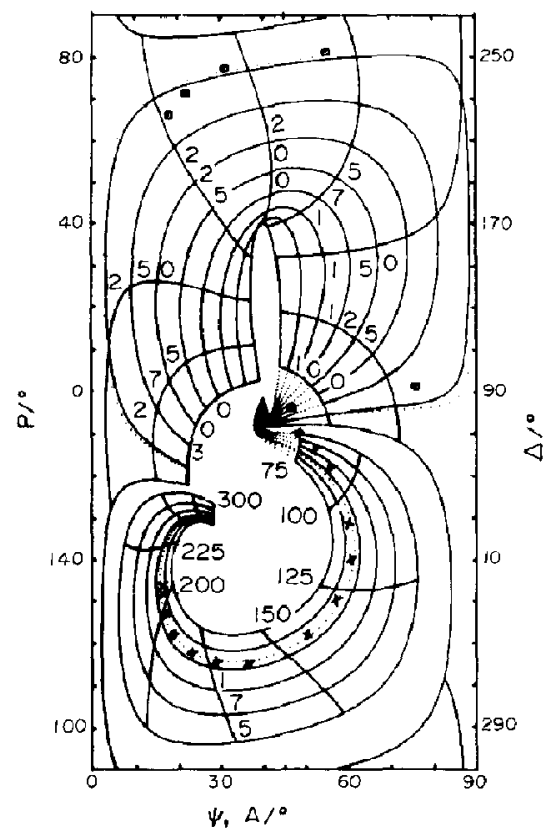

Fig. 1. $P$ vs $A$ plots computed for thickness in the range 0 $<d<300 \mathrm{~nm}$, and the following equations: (i) $\bar{n}_{f}=1.5116$ $-\mathrm{i} 0.1418$ (dotted line) and $0<k_{f}<0.16$ (solid line); (ii) $\bar{n}_{f}$ $=1.5613-\mathrm{i} 0.2676$ (dotted line) and $0.20 \cong k_{j} \cong 0.30$ (solid line). Experimental points resulting for the hydrous Ag(I) oxide layer formed at $20 \mathrm{mVs}^{-1}$ (回) and at $0.2 \mathrm{mVs}^{-1}(\mathrm{x})$. $25^{\circ} \mathrm{C}$. 


\section{Calculation procedure}

The complex refractive index $\left(\bar{n}_{f}\right)$ of the anodic layer is given by $\left(\bar{n}_{f}=n_{f}-i k_{f}\right)$ where $n_{f}$ is the real part of the refraction index and $k_{f}$ is the absorption coefficient. For a single homogeneous layer $\bar{n}_{f}$ changes monotonously with the layer thickness $(d)$, the rate of change being relatively faster as $d$ tends to zero. On the other hand, for a multilayer structure, the change of $n_{j}$ and $d$ is either discontinuous or rather involved depending on the complex refraction indexes of the different layers. In this case, actually representative $n_{f}$, $k_{f}$ and $d$ values can be obtained through a sound processing of data.

Ellipsometric data are frequently interpreted on the basis that the optical constants remain nearly unchanged within a certain range of the layer thickness[27] and the reliability in the calculation of the different parameters can be increased by increasing the number of data and by decreasing the number of the unknown parameters. Thus, a single point in the $P$ vs $A$ plane is ambiguously defined by a set of $n_{f}, k_{f}$ and $d$ values. But, when a number of points $(N)$ in the $P$ vs $A$ plane can be adjusted to a single function with common $n_{f}$ and $k_{f}$ values, there are $2 N$ known data and only $(N+2)$ unknown parameters, among which the values of $d$ are included. The latter can frequently be correlated to the anodic or cathodic charge involved in the layer electroforming process. This additional function becomes particularly useful to solve the problem and, eventually to confirm the results.

For an anodic layer whose thickness increases progressively, the calculation procedure consists in grouping a sufficiently large number of ellipsometric data which can be correlated for common values of $n_{f}$ and $k_{f}$. These values can also be employed to adjust other groups of data. This can be taken as an indication that both the composition and structure of the growing layer remain independent of the layer thickness.

Data obtained at 0.2 and $20 \mathrm{mV} \mathrm{s}^{-1}$ were dealt in groups of a minimum of four successive points each for the application of conventional iterative methods. The whole data either at 0.2 or at $20 \mathrm{mV} \mathrm{s}^{-1}$ can be satisfactorily correlated with the same $n_{f}$ and $k_{f}$ values throughout the whole range of $d$ values of the anodic layer (Fig. 1). The optical parameters of the anodic layer formed at $0.2 \mathrm{mV} \mathrm{s}^{-1}$ are expressed by the equation $\bar{n}_{f}=1.5613-\mathrm{i} 0.2676$. Theoretical curves were obtained for $0 \leqslant k_{f} \leqslant 0.30$ and $0 \leqslant d \leqslant 300 \mathrm{~nm}$. At $20 \mathrm{mVs}^{-1}$ a satisfactory adjustment of the experimental data is achieved with the equation $\bar{n}_{f}=1.5116$ - i0.1418 for average layer thicknesses between 2.9 and $224 \mathrm{~nm}$. This data processing provides an accurate estimation of the average value of $d$ for the hydrous $\mathrm{Ag}(\mathrm{I})$ oxide layer formed in alkaline electrolyte. The adjustment of results can be considered as very good for the range of $d$ between 80 and $225 \mathrm{~nm}$. The uncertainty of the adjustment of results increases as the average layer thickness decreases because, for very thin layers the homogeneity condition is probably no longer valid [15] and in this case, the proper single layer model becomes relatively insensitive to changes in either $n_{f}, k_{f}$, or $d$.

The influence of the voltammetric anodic charge $\left(Q_{a}\right)$ on the $P$ us $A$ plots was computed from the adjustment of ellipsometric plots through the values of $d$ either independently of $Q_{a}$ or by assuming that $d$ is directly proportional to $\mathcal{Q}_{a}$. From the adjustment of experimental and computed data a linear relationship between the $Q_{a}$ and $d$ is observed at $20 \mathrm{mV} \mathrm{s}^{-1}$ (Fig. 2). Conversely, at $0.2 \mathrm{mVs}^{-1}$ a clear deviation from linearity is observed for $Q_{a}$ greater than $30 \mathrm{mC} \mathrm{cm}^{-2}$. These results indicate that at a lowest $v$, after the initial accumulation of anndic product yielding $\mathrm{Ag}(\mathrm{I})$ oxide, during the potential cycling there is an increasing contribution of charge related to the electroformation of soluble Ag(I) species.

The slope of the $Q_{a}$ os $d$ straightline plot at $20 \mathrm{mVs}^{-1}$ is $2.35 \mu \mathrm{Ccm}^{-2} \mathrm{~nm}^{-1}$ but for data at $0.2 \mathrm{mV} \mathrm{s}^{-1}$ this linear relationship is only obeyed when $Q_{a}$ is smaller than $30 \mathrm{mC} \mathrm{cm}^{-2}$. At $20 \mathrm{mV} \mathrm{s}^{-1}$ practically no soluble $\mathrm{Ag}(\mathrm{I})$ charge contribution can be detected throughout these measurements but at $0.2 \mathrm{mV} \mathrm{s}^{-1}$ the time involved during the voltammetric electroformation process is sufficiently large to enhance the formation of soluble $\mathrm{Ag}(\mathrm{I})$.

\section{Rotating ring-disc electrode data}

Both the voltammogram in $0.1 \mathrm{M} \mathrm{NaOH}$ at the disc and correspondingly, the current at the ring depend on $v$. During the positive potential excursion at $3 \mathrm{mVs}^{-1}$, the cathodic current at the ring starts when the first stage of silver electrooxidation occurs. This cathodic current reaches a maximum in the potential range of the ascending branch of the main anodic peak, and finally, decays to a limiting value ( $c a) 0.6 \mu \mathrm{A}$ at $3000 \mathrm{rpm}$ ) which is maintained during the reverse potential scan. This limiting current is independent of $v$ but increases linearly with $\omega^{1 / 2}$ as earlier reported [11]. The null current is only attained when the potential becomes more negative than that of the hydrous $\mathrm{Ag}(\mathrm{I})$ oxide electroreduction peak.

A different response is observed at $30 \mathrm{mV} \mathrm{s}^{-1}$. In this case, during the positive potential excursion the cathodic current initially behaves similar to that referred to at $3 \mathrm{mV} \mathrm{s}^{-1}$. But later two cathodic current maxima are defined, and afterwards the current goes through zero and becomes anodic in a short potential range. During the reverse potential scan the ring current again becomes cathodic to attain, finally, the same limiting current already mentioned at $3 \mathrm{mV} \mathrm{s}^{-1}$. The limiting current lasts during the negative potential scan until the potential where the hydrous $\mathrm{Ag}(\mathrm{I})$ oxide

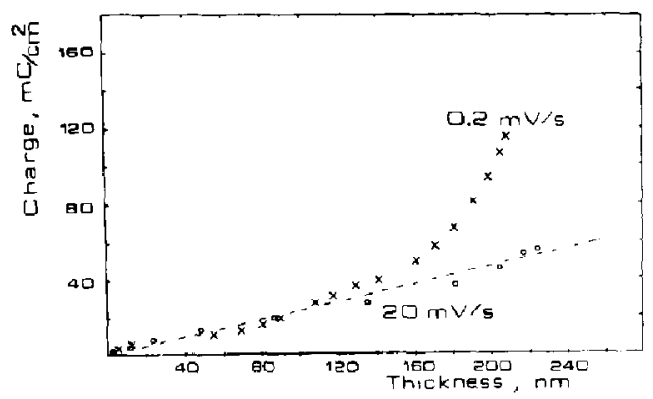

Fig. 2. $Q_{d} v s$ thickness calculated from ellipsometric data; $(x)$ hydrous $\mathrm{Ag}(\mathrm{I})$ oxide layer formed at $0.2 \mathrm{mVs}^{-1}$ and $(\square)$ at $20 \mathrm{mVs}^{-1} \cdot 25^{\mathrm{c}} \mathrm{C}$. 
electroreduction is reached. At this point the current at the ring becomes anodic till the potential at the disc exceeds that of the hydrous $\mathrm{Ag}(\mathbf{I})$ oxide electroreduction. Later, a net cathodic current peak is recorded at the ring while the complete hydrous $\mathrm{Ag}$ (I) oxide electroreduction is accomplished in the disc.

Runs made in $0.1 \mathrm{M} \mathrm{NaOH}+1 \mathrm{M} \mathrm{NaClO}_{4}$ show similar current plateaux for the dissolution rate once a complete layer of hydrous $\mathbf{A g}(\mathbf{I})$ oxide has been produced, although the distribution of voltammetric current peaks depends on the solution composition.

\section{DISCUSSION}

The ellipsometric and the rotating ring-disc electrode data are consistent with the formation of soluble $\mathrm{Ag}(\mathrm{I})$ during the electrooxidation of silver in alkaline solutions yielding hydrous $\mathbf{A g}(\mathbf{I})$ oxide. The current peak observed at the ring electrode is directly related to the Faradaic process taking place at the disc electrode. During the current flow at the ring caused by the Faradaic process at the disc the initial Pt ring electrode turns into a silver-plated Pt-ring electrode. This means that two types of processes must be distinguished at the ring electrode, one associated with the electrochemical reactions resulting from the electroreduction of soluble Ag(I) formed at the disc during the voltammetric scan, and another for silver electrodeposit at the ring electrode, in contact with the alkaline electrolyte.
During the positive potential scan as the first level silver electrooxidation threshold potential is reached an injection of soluble $\mathbf{A g}(\mathbf{I})$ into solution takes place and once the potential range of the complex anodic voltammetric peak is exceeded, a steady dissolution current is established whose average value is $0.6 \mu \mathrm{A}$, at $3000 \mathrm{rpm}$. The fact that this figure is independent of $v$, but increases directly proportional to $\omega^{1 / 2}$ suggests that the solution remains $\mathrm{Ag}_{2} \mathrm{O}$ saturated at the reaction interface[ 7,11$]$.

The supersaturation level in the first part of the positive-direction potential sweep has been estimated as nearly twice the $\mathrm{Ag}_{2} \mathrm{O}$ solubility[11]. These results can be used to explain the $Q_{a} v s d$ plots resulting from the ellipsometric measurements at different $v$ (Fig. 2). The solubility of $\mathrm{Ag}_{2} \mathrm{O}$ goes through a minimum with increasing $\mathrm{pH}$ and the dominant species changes from the cation $\mathrm{Ag}^{+}$to the anion $\mathrm{Ag}(\mathrm{OH})_{2}^{-}$. The minimum occurs at about $\mathrm{pH} 12-13$ with a solubility of 2 $\times 10^{-6} \mathrm{~mol} \mathrm{~kg}^{-1}[18,21]$ which is independent of the presence of salts $\left(\mathrm{NaClO}_{4}\right)[28]$.

Despite the difference in the hydrodynamics of rrde and ellipsometric runs, the following estimation and comparison of the electrodissolution current can be made. A dissolution current of $0.6 \mu \mathrm{A}$ at the ring makes the silver dissolution current at the disc equal to $2.4 \mu \mathrm{A}$, which corresponds to $19 \mu \mathrm{A} \mathrm{cm}^{-2}$. At $0.2 \mathrm{mV} \mathrm{s}^{-1}$, if the ime consumed by the anodic process is about $500 \mathrm{~s}$, then the anodic charge for the silver dissolution reaction is $9.5 \mathrm{mC} \mathrm{cm}^{-2}$. On this basis a correction to

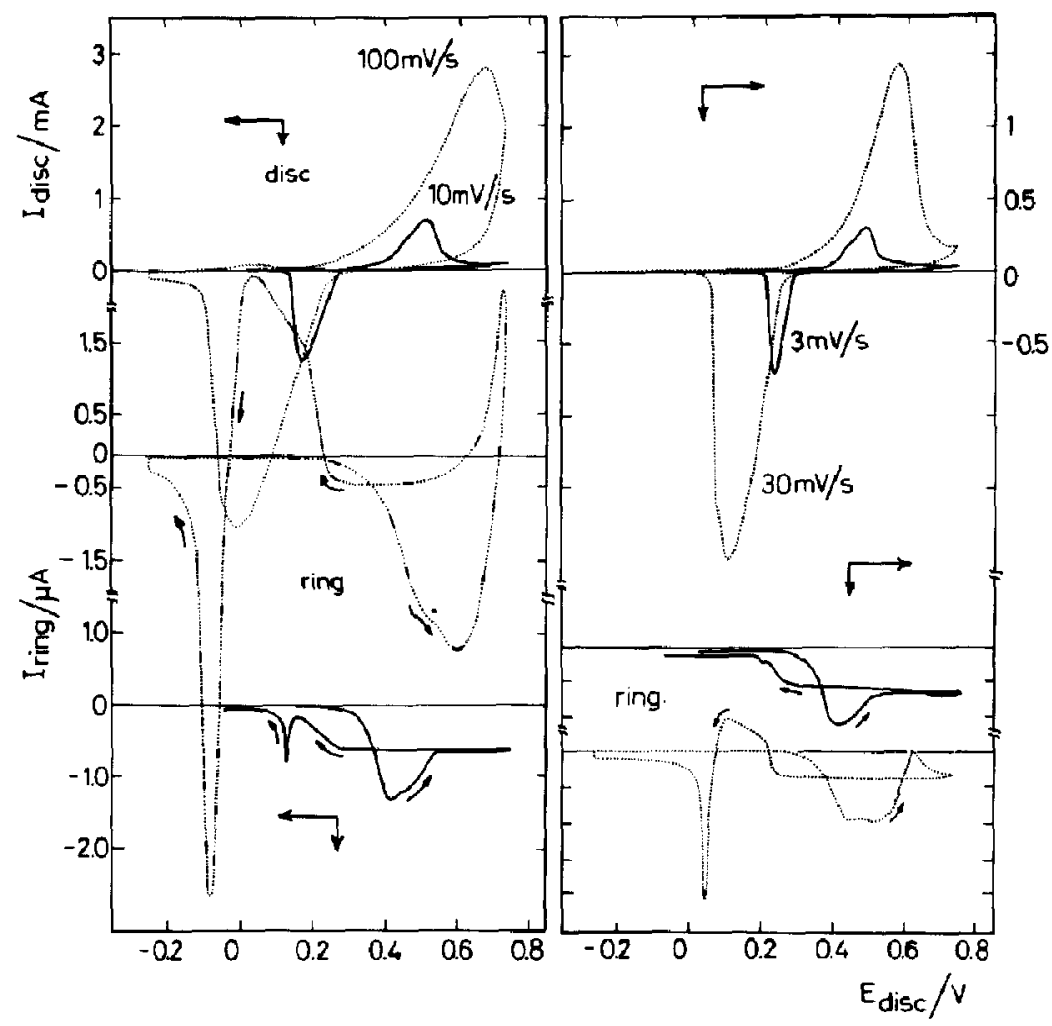

Fig. 3. Voltammograms at the disc electrode for different $v$ and simultaneous current responses at the ring electrode at $E_{\text {ring }}=0.12 \mathrm{~V}$; rotation speed $3000 \mathrm{rpm} .25^{\circ} \mathrm{C}$. 
the charge $Q_{a}$ should be made. Obviously, this correction decreases as the potential sweep rate increases, After introducing this cor ection the $Q_{a} v s d$ plots resulting at different values of $v$ are now coincident on a single straight line (Fig. 2). The slope of the common straight line is $2.35 \mu \mathrm{C} \mathrm{cm}^{-2} \mathrm{~nm}^{-1}$, indicating that either a hydrous relatively compact or a porous hydrous silver oxide layer is formed. The slope expected for an anhydrous silver oxide layer (density $\left.7.143 \mathrm{~g} \mathrm{~cm}^{-3}[9,20,29]\right)$ is $5.95 \mu \mathrm{C} \mathrm{cm}^{-2} \mathrm{~nm}^{-1}$.

This conclusion is consistent with the fact that different sets of optical constants are obtained at 0.2 or $20 \mathrm{mV} \mathrm{s}^{-1}$ independently of the anodic layer thickness. As $v$ increases the optical constants decrease as expected for an increasing porosity of the anodic layer.

The porous characteristics of the hydrous $\mathbf{A g}(\mathbf{I})$ oxide have been postulated by many authors $[12,15,21]$. The present data allow the estimation of a volume 2.5 times greater than the one currently admitted for the bulk oxide[9,20,29], and show that the hydrous $\mathrm{Ag}(\mathrm{I})$ oxide grows developing a "freezing in" state[30] whose grade of porosity depends on the sweep rate applied.

The characteristics of the hydrous $\mathrm{Ag}(\mathrm{I})$ oxide structure discussed above must be taken in to account in the interpretation of the kinetics of the oxide growth under different potential perturbation conditions.

\section{CONCLUSIONS}

(1) Ellipsometric data confirm that two anodic layers of different optical constants are electroformed during the potentiodynamic electrooxidation of silver in alkaline solution, depending on the potential perturbation conditions. The corresponding complex refractive indexes are $n=1.5613-i 0.2676$ for $0.2 \mathrm{mVs}^{-1}$ and $\bar{n}=1.5116-\mathrm{i} 0.1418$ for $20 \mathrm{mV} \mathrm{s}^{-1}$, respectively.

(2) The hydrous $\mathrm{Ag}(\mathrm{I})$ oxide anodically formed behaves as a porous structure with a capacity of charge estimated of about $40 \%$ of the anhydrous oxide[25] and, consequently, an average thickness of about 2.5 times greater.

(3) The electroformation of the hydrous $\mathrm{Ag}(\mathrm{I})$ oxide layer is coupled to a $\mathbf{A g}(\mathrm{I})$ electrodissolution[7-11].

(4) The influence of sweep rate in the characteristics of the anodic layer supports previous interpretations based on changes in the degree of water content in the layer. The water content increases accordingly to the potential sweep rate.

(5) The rate for the electrochemical dissolution of silver as $\mathbf{A g}(\mathrm{I})$ is independent of the potential sweep rate.

Acknowledgement-INIFTA is a Research Institute jointly established by the Universidad Nacional de La Plata, the Consejo Nacional de Investigaciones Científicas y Técnicas and the Comisión de Investigaciones Científicas de la Provincia de Buenos Aires. This work was partially supported by the Regional Program for the Scientific and Technological Development of the Organization of the American States.

\section{REFERENCES}

1. E. B. Brik, R. M. Lazorenko-Manevich and Ya. M. Kolotyrkin, Elektrokhimiya 13, 1520 (1977).

2. G. T. Burstein and R. C. Newman, Electrochim. Acta 25, 1009 (1980).

3. N. A. Hampson, K. I. MacDonald and J. B. Lee, J. electroanal. Chem. 45, 149 (1973).

4. R. Kötz and B. E. Hayden, Surf. Sci. 135, 374 (1983); C. A. Fenstermaker and F. L. McCrakin, Surf. Sci. 16, 85 (1969).

5. Z. I. Kudryavtseva, V. A. Openkin, N. A. Zhuchkova and N. A. Shumilova, Elektrokhimiya 14, 517 (1978).

6. G. V. Zhutaeva and N. A. Shumilova, Elektrokhimiya 4, 99 (1968).

7. J. Ambrose and R. G. Barradas, Electrochim. Acta 19, 781 (1974).

8. J M. M. Droog and F. Huisman, J elertroanal Chem 115, 211 (1980); J. M. M. Droog, J. electroanal. Chem. 115,225 (1980).

9. J. M. M. Droog, P. T. Alderliesten and G. A. Bootsma, J electroanal. Chem. 99, 173 (1979).

10. M. Hepel and $M$. Tomkiewiez, J. electrochem. Soc. 131, 1288 (1984).

11. B. Miller, J. electrochem. Soc. 117, 491 (1970)

12. A. Hickling and D. Taylor, Discuss. Faraday Soc. 1, 277 (1947).

13. T. G. Clarke, N. A. Hampson, J. B. Lee, J. R. Morley and B. Scanlon, Ber. Bunsen, phys. Chem. 73, 279 (1969)

14. A. I. Oshe, Elektrakhimiya 4, 1214 (1968).

15. G. W. D. Briggs, M. Fleischmann, D. J. Lax and H. R. Thirsk. Trans. Faraday Soc. 64, 3120 (1968); M. Fleischmann, D. J. Lax and H. R. Thirsk, Trans. Faraday Soc. 64, 3128 (1968).

16. R, D. Giles and J. A. Harrison, J. electroanal. Chem, 27, $161(1970)$, R. D. Giles, J. A. Harrison and H. R. Thirsk, J. electroanal. Chem. 22, 375 (1969).

17. B. V. Tilak, R. S. Perkins, H. A. Kozlowska and B. E. Conway, Electrochim. Acta 17, 1447 (1972); Electrochim. Acta 17, 1471 (1972).

18. B. G. Pound, D. D. MacDonald and J. W. Tomlinson Electrochim. Acta 24, 929 (1979); Electrochim. Acta 25, 563 (1980); Electrochim Acta 25, 1293 (1980); Electrochim Acta 27, 1489 (1982).

19. P. Stonehart, Electrochim. Acta 13, 1789 (1968).

20. M. J. Dignam, H. M. Barrett and G. D. Nagy, Can. J. Chem. 47, 4253 (1969).

21. T. P. Dirkse, J. electrochem. Soc. 106, 453 (1959).

22. T. P. Dirkse and D. B. De Vries, J. phys. Chem. 63, 107 (1959).

23. R. H. Muller and C. G. Smith, Surf. Sci, 96, 375 (1980).

24. M. Lopez Teijelo, J. R. Vilche and A. J. Arvia, J. electroanal. Chem. 162, 207 (1984).

25. M. Lupes Teijelu, J. O. Zerbinu, J. R. Vilche and A. J. Arvia, Electrochim. Acta 29, 939 (1984)

26. D. B. Gibbs, B. Rao, R. A. Griffin and M. J. Dignam, J. electrochem. Soc. 122, 1167 (1975).

27. G. Blondeau, M. Froelicher, M. Froment, A. Hugot + Le Goff and J. O. Zerbino, J. electrochem. Soc., 126, 1592 (1979).

28. H. L. Johnston, F. Cuta and A. B. Garrett, J. Am. chem. Sac. 55, 2311 (1933).

29. R. C. Weast (Editor), Handbook of Chemistry and Physics, 60th ed. CRC, Cleveland, Ohio (1980).

30. W. J. Hamer and D. N. Craig, J. electrochem. Soc. 104, 206 (1957). 